\title{
Erratum to: Prescribing pattern and resource utilization of monoamine oxidase-B inhibitors in Parkinson treatment: comparison between rasagiline and selegiline
}

\author{
Luca Degli Esposti ${ }^{1}$ - Carlo Piccinni ${ }^{2} \cdot$ Diego Sangiorgi $^{1} \cdot$ Flavio Nobili $^{3}$ • \\ Stefano Buda ${ }^{1}$
}

Published online: 20 February 2016

(c) Springer-Verlag Italia 2016

\section{Erratum to: Neurol Sci (2016) 37:227-234}

\section{DOI 10.1007/s10072-015-2395-7}

The author would like to correct the following error in the online publication of the article.

In page 233, under the second paragraph of "Limitation" section, the following sentence has not to be considered: "An additional limitation is related to the differences in labelling of the two studied drugs: rasagiline is indicated also as monotherapy, whereas selegiline only as add-on therapy. This difference could have influenced our results." because both these drugs are authorized by Italian Medicines Agency (AIFA) either as monotherapy or in combination in patients with Parkinson's disease.

The online version of the original article can be found under doi:10.1007/s10072-015-2395-7.

Luca Degli Esposti

luca.degliesposti@clicon.it;

http://www.clicon.it

1 CliCon Srl, Health, Economics and Outcomes Research, Via Salara, 36, 48100 Ravenna, Italy

2 Department of Medical and Surgical Sciences, Pharmacology Unit, University of Bologna, Bologna, Italy

3 Clinical Neurology, Department of Neuroscience (DINOGMI), University of Genoa, Genoa, Italy 